\title{
Improving biopharmaceutical properties of Vinpocetine through cocrystallization
}

\author{
SAMUEL GOLOB ${ }^{1}$, MIRANDA PERRY ${ }^{2}$, MATTEO LUSI ${ }^{2}$, MICHELE REMO \\ CHIEROTTI ${ }^{3}$, ISTOK GRABNAR ${ }^{4}$, LUCIA LASSIANI $^{1}$, DARIO VOINOVICH ${ }^{{ }^{*}}$, \\ MICHAEL J. ZAWOROTKO ${ }^{2 *}$ \\ ${ }^{1}$ Department of Chemical and Pharmaceutical Sciences, University of Trieste, Italy \\ ${ }^{2}$ Department of Chemical \& Environmental Sciences, University of Limerick, Limerick, Republic \\ of Ireland \\ ${ }^{3}$ Department of Chemistry and NIS Centre, University of Torino, Torino, Italy \\ ${ }^{4}$ Faculty of Pharmacy, University of Ljubljana, Askerceva 7, SI-1000 Ljubljana, Slovenia.
}

\begin{abstract}
:
Vinpocetine is a poorly water soluble weakly basic drug $\left(\mathrm{pK}_{\mathrm{a}}=7.1\right)$ used for the treatment of several cerebrovascular and cognitive disorders. Since existing formulations exhibit poor bioavailability and scarce absorption, a dosage form with improved pharmacokinetic properties is highly desirable. Cocrystallization represents a promising approach to generate diverse novel crystal forms and to improve the aqueous solubility and in turn the oral bioavailability. In this paper, a novel ionic cocrystal of vinpocetine is described, using boric acid as a coformer, and fully characterized (by means of DSC, solid-state NMR, powder and single crystal XRD, and Powder Dissolution Test). Pharmacokinetic performance was also tested in a human pilot study. This pharmaceutical ionic cocrystal exhibits superior solubilization kinetics and modulates
\end{abstract}


important pharmacokinetic values such as $\mathrm{t}_{\max }, \mathrm{c}_{\max }$ and $\mathrm{AUC}$ of the poorly soluble vinpocetine and it therefore offers an innovative approach to improve its bioavailability.

Keywords: Ionic Cocrystal; Vinpocetine; Boric Acid; Bioavailability; Pharmacokinetics

* Correspondence to: Voinovich Dario (email: vojnovic@units.it); Mike Zaworotko (email: xtal@ul.ie ; ph: +353 61 234361; cell: +353 868144150) 


\section{INTRODUCTION}

Crystalline forms are the preferred dosage forms for active pharmaceutical ingredients (APIs) for use in drug products. Generally single and multicomponent crystals show superior stability to their amorphous counterparts and their synthesis (crystallization) tends to afford highly pure products that are reproducible and scalable. ${ }^{1}$ Moreover, different crystal forms can exhibit different physicochemical properties that will affect the pharmacokinetics of the drug. For these reasons, during the early stages of drug development, novel crystal forms of the API are searched for through screening processes and their physicochemical properties are identified. ${ }^{2-9}$ These novel crystal forms might include polymorphs or multi-component crystal such as salts, solvates, hydrates and, more recently, cocrystals. Cocrystals are solids that are crystalline single phase materials composed of two or more different molecular and/or ionic compounds, generally in a stoichiometric ratio, which are neither solvates nor simple salts. ${ }^{10}$ The current attraction to cocrystals as novel crystal forms is attributed to their ability to change key properties of APIs via inclusion of additional molecules through reliable, therefore designable, interactions (i.e. supramolecular synthons) ${ }^{11}$. A large library of potential coformers can be built using databases containing pharmaceutically approved substances such as the GRAS (generally recognized as safe) list for example, which contains ingredients recognized by the United States Food and Drug Administration (FDA) to be safe under specified conditions. These substances can serve as

coformers in order to obtain new crystal forms with improved solubility, ${ }^{12,13}$ compressibility, ${ }^{14}$ or stability ${ }^{15}$ that ultimately impact on bioavailability. ${ }^{16}$

The main challenge during pharmaceutical cocrystal development is the rational selection of coformers for a particular drug molecule, since it is not realistic to screen the whole chemical 
catalogue. Following a proven crystal engineering ${ }^{17}$ approach, possible coformers can be chosen to form robust supramolecular interactions (synthons) with the desired drug molecule, taking into consideration supramolecular synthon hierarchy. ${ }^{18}$ This supramolecular synthesis strategy ${ }^{11,19}$ primarily relies on crystallographic data found in the Cambridge Structural Database (CSD) ${ }^{20}$ This approach, however, has yet to offer clear predictions about whether there will be desirable property improvement in the resulting cocrystals, even though efforts have been made to correlate the physicochemical properties of coformers to those of the resulting cocrystals. ${ }^{21}$ In particular, amongst pharmaceutical cocrystals, ionic co-crystals have proven to be a viable route to enhance solubility/bioavailability of poorly soluble drugs. ${ }^{22}$ Recently, a pharmaceutical ionic cocrystal containing two active ingredients, Entresto ${ }^{\mathrm{TM}}$ used to treat chronic heart failure, gained approval from the FDA. ${ }^{23}$

The target of this study, vinpocetine (Figure 1), is a semisynthetic derivative of the natural alkaloid vincamine, showing a series of pharmacological properties in relation to cerebral circulation and on vascular resistance, particularly in the area of blood vessels. ${ }^{24}$ Vinpocetine has been shown to impact the cerebral circulation and metabolism and improve various types of cerebrovascular circulatory disorders such as the cerebral infarction, cerebral hemorrhage, cerebral arteries cirrhosis ${ }^{25}$ and for the long term treatment of cognitive disorders and related symptoms. ${ }^{26}$ Due to its low aqueous solubility, and extensive first pass metabolism, vinpocetine presents low oral bioavailability $(\sim 6.7 \%)^{27,28}$ and, as a consequence, its clinical use is limited. In this context the aim of this investigation is to improve the solubility and bioavailability of vinpocetine with an ionic cocrystal. 


\section{MATERIALS AND METHODS}

\section{Materials}

Vinpocetine E.P. grade was a kind gift from Linnea SA (Riazzino-Locarno, $\mathrm{CH}$ ) with a purity of 99.8\% and was used without further purification. Boric acid was supplied by Sigma-Aldrich (St Louis, MO, USA) and used without further purification. Acetonitrile with a purity of $99.9 \%$ was supplied by Sigma-Aldrich (St Louis, MO, USA)

\section{Synthesis of Vinpocetine - Boric acid Cocrystal (1)}

1 was prepared by slow evaporation using the following procedure: a mixture of vinpocetine (50.1 $\mathrm{mg}, 0.14 \mathrm{mmol})$ and boric acid $(26.1 \mathrm{mg}, 0.42 \mathrm{mmol})$ was transferred into a glass vial. Subsequently, $14 \mathrm{~mL}$ of acetonitrile was added to the solid mixture and stirred for $30 \mathrm{~min}$ at 45 ${ }^{\circ} \mathrm{C}$. The clear solution was then left for slow evaporation under ambient conditions.

\section{Crystal Form Characterization}

\section{Single-Crystal X-Ray Diffraction}

Single-crystal analysis for $\mathbf{1}$ was performed on a Bruker-AXS D8 QUEST diffractometer (Bruker, Madison, WI, USA) using a micro focus generator of Mo $\operatorname{K} \alpha$ radiation $(\lambda==0.71073$ $\AA$ A) and CMOS PHOTON detector. Data for 1 were collected at $100 \mathrm{~K} ¥$. Lattice parameters were determined from least-squares analysis, and reflections were integrated using SAINT (Bruker, Madison, WI, USA). ${ }^{29}$ The structure was solved by direct methods and refined by full matrix least squares based on $F^{2}$ using X-Seed software. ${ }^{30}$ All non-hydrogen atoms were anisotropically refined. All hydrogen atoms bonded to carbon, nitrogen, and oxygen atoms were placed 
geometrically and refined with an isotropic displacement parameter fixed at 1.2 times $U q$ of the atoms to which they were attached. Hydrogen atoms bonded to methyl groups were placed geometrically and refined with an isotropic displacement parameter fixed at 1.5 times $U q$ of the carbon atoms.

\section{Powder X-ray Diffraction (PXRD)}

The cocrystal structure of $\mathbf{1}$ was characterized using a D8 Bruker X-ray Powder Diffractometer (Bruker, Madison, WI, USA) using $\mathrm{Cu}$ K $\alpha$ radiation $(\lambda=1.54178 \AA$ ) $, 40 \mathrm{kV}, 40 \mathrm{~mA}$. Data were collected at room temperature on a sample manually ground in an agate mortar. The data were collected over an angular range of $5^{\circ}$ to $40^{\circ} 2 \theta$ value in continuous scan mode using a step size of $0.05^{\circ} 2 \theta$ value and a scan rate of $5^{\circ} / \mathrm{min}$.

Moreover, a calculated PXRD diffractogram was generated from the single-crystal structure of $\mathbf{1}$ using Mercury 2.2 (Cambridge Crystallographic Data Centre, Cambridge, UK) and compared with the pattern obtained from the bulk sample.

\section{Differential Scanning Calorimetry (DSC)}

Differential Scanning Calorimetry was performed on a PerkinElmer Diamond differential scanning calorimeter (PerkinElmer, Waltham, MA, USA) with a scan range of $25{ }^{\circ} \mathrm{C}-250{ }^{\circ} \mathrm{C}$, scan rate of $10^{\circ} \mathrm{C} / \mathrm{min}$ under nitrogen atmosphere.

\section{Solid-state NMR spectroscopy (SSNMR)}

Solid-state NMR spectra were recorded with a Bruker Advance II 400 instrument operating at 400.23, 100.64 and 40.55 MHz for ${ }^{1} \mathrm{H},{ }^{13} \mathrm{C}$ and ${ }^{15} \mathrm{~N}$ nuclei, respectively. Cylindrical $4 \mathrm{~mm}$ o.d. 
zirconia rotors with a sample volume of $80 \mu \mathrm{L}$ were employed and spun at $12\left({ }^{13} \mathrm{C}\right)$ or $9\left({ }^{15} \mathrm{~N}\right)$ kHz. All ${ }^{13} \mathrm{C}$ and ${ }^{15} \mathrm{~N}$ experiments employed the RAMP-CP pulse sequence $\left({ }^{1} \mathrm{H} 90^{\circ}\right.$ pulse of 3.05

$\mu$ ) with TPPM ${ }^{1} \mathrm{H}$ decoupling with an rf field of $75 \mathrm{kHz}$ during the acquisition period. ${ }^{13} \mathrm{C}$ spectral editing experiments were performed with the CPPISPI pulse sequence with polarization inversion times of 65 and $70 \mu$ s for pure vinpocetine and $\mathbf{1}$, respectively in order to obtain $\mathrm{CH}_{3}$ and $\mathrm{C}_{\mathrm{q}}$ positives, $\mathrm{CH}$ nulls and $\mathrm{CH}_{2}$ negatives. ${ }^{13} \mathrm{C}$ and ${ }^{15} \mathrm{~N}$ chemical shifts were referenced with the resonance of hexamethylbenzene $\left({ }^{13} \mathrm{C}\right.$ methyl signal at $\left.17.4 \mathrm{ppm}\right)$ and $\left(\mathrm{NH}_{4}\right)_{2} \mathrm{SO}_{4}\left({ }^{15} \mathrm{~N}\right.$ signal at $-355.8 \mathrm{ppm}$ with respect to $\mathrm{CH}_{3} \mathrm{NO}_{2}$ ).

\section{Powder Dissolution Test (PDT)}

Prior to dissolution test, the equilibrium solubility was determined at $25^{\circ} \mathrm{C}$ adding an excess of powder to $20 \mathrm{ml}$ of $0.2 \mathrm{M} \mathrm{KH}_{2} \mathrm{PO}_{4} / 0.2 \mathrm{M} \mathrm{NaOH}$ (pH 7.4) buffer. The equilibration time was found to be $24 \mathrm{~h}$. The dissolution experiments of pure vinpocetine and $\mathbf{1}$ were performed using $100 \mathrm{ml}$ of $\mathrm{pH} 7.4$ buffer since in previous studies ${ }^{31}$ it was reported that vinpocetine solubility is highly $\mathrm{pH}$ dependent, and is particularly low at intestinal $\mathrm{pH}$ values. Each experiment was performed at $37{ }^{\circ} \mathrm{C}$ to mimic body temperature. Additionally, the dissolution tests were performed using non-sink conditions to build up the supersaturation, as commonly occurs under finite volume conditions in the gastrointestinal tract, and to allow for possible events such as nucleation, crystallization and precipitation to $\operatorname{proceed}^{32}$. Accordingly, at time zero, a suitable amount of sample (pure drug or cocrystal 1) to give $15 \mathrm{mg}$ of active ingredient, was added to 100 $\mathrm{ml}$ phosphate buffer at $37^{\circ} \mathrm{C}$. The crystalline materials were previously sieved and only the powder with a particle size between 50 and $70 \mu \mathrm{m}$ was used during the dissolution experiments. Each test lasted $5 \mathrm{~h}$, and the uniformity of conditions was constantly ensured by using an impeller 
at a stirring rate of $200 \mathrm{rpm}$. The equilibrium solubility and the amount of vinpocetine solubilized at each time point was quantified by the previously described method ${ }^{33}$. Each formulation was tested in triplicate.

\section{In Vivo absorption studies}

For the in vivo study six male volunteers aged between 28 and 55 years were chosen. The study was conducted at the University of Trieste, Italy, following the principles of the Declaration of Helsinki and the International Conference on Harmonization Guidelines. Before the study, a written informed consent was signed by each subject. All the volunteers were prohibited to take medicines, following a one week wash out period before the beginning of the present study.

The dose of $10 \mathrm{mg}$ of vinpocetine was administered in a hard gelatin capsule (type 0) with 200 $\mathrm{mL}$ of water. After one week of washout period the same procedure was adopted for the test formulation, administering a hard gelatin capsule containing $14 \mathrm{mg}$ cocrystal $\mathbf{1}$, corresponding to $10 \mathrm{mg}$ of vinpocetine. Blood samples $(5 \mathrm{ml})$ were collected in heparinized tubes at interval times of $0,1.5,2,2.5,3,3.5,4,4.5$, and $5 \mathrm{~h}$ following capsule administration. The collected samples were immediately separated by centrifugation at $2400 \mathrm{~g}$ for $10 \mathrm{~min}$, subsequently frozen and stored at $-40^{\circ} \mathrm{C}$ until assayed.

In this study, apovincaminic acid plasma concentrations were monitored, as suggested in the literature $^{34}$. This choice was made in consideration of the fast metabolic conversion from vinpocetine to apovincaminic acid.

The determination of apovincaminic acid concentration was performed using a previously published HPLC method ${ }^{34}$. The preparation of the samples for HPLC analysis was performed according to the method reported by Hasa et $\mathrm{al}^{33}$. Briefly, $600 \mu \mathrm{l}$ methanol were added to $200 \mu 1$ 
plasma, and the resulting mixture was vortexed for $10 \mathrm{~min}$. After centrifugation $(2400 \mathrm{~g}$ for 6 $\min ), 5 \mu l$ of the organic solution was injected.

\section{Pharmacokinetic Analysis}

A compartmental pharmacokinetic analysis was performed using ADAPT 5 software ${ }^{35}$. One- and two-compartment models with and without absorption lag-time were evaluated and onecompartment model with absorption lag-time was selected for the analysis based on favorable value of Akaike information criterion. The estimated parameters were absorption $\left(\mathrm{t}_{1 / 2 \mathrm{Ka}}\right)$ and elimination $\left(\mathrm{t}_{1 / 2 \mathrm{Ke}}\right)$ half-lives, absorption lag time $\left(\mathrm{t}_{\text {lag }}\right)$ and apparent distribution volume $\left(\mathrm{V}_{\mathrm{d}} / \mathrm{F}\right)$. Bioavailability parameters, including maximum concentration in plasma $\left(\mathrm{C}_{\max }\right)$, time to maximum concentration $\left(\mathrm{t}_{\max }\right)$, and area under the plasma concentration-time curve (AUC) were calculated as secondary parameters.

The relative bioavailability after oral administration (Frel) was calculated in Eq. 1:

Frel $=$ AUC1 / AUC(vinpocetine $)$

Descriptive statistics were calculated, and results are reported as means (standard errors). As this was a pilot study, the results were not subjected to any formal statistical test.

\section{RESULTS AND DISCUSSION}

The potential coformers to cocrystalize with vinpocetine were selected through a supramolecular synthon approach. Vinpocetine is characterized by a tertiary amine and an ester functions that could both act as H-bond acceptors. Hence molecules with H-bond donor groups, such as alcohols and mildly acidic carboxylic acids could be ideal coformer candidates. With this in mind we created a coformer library consisting of GRAS listed substances with hydroxyl functions, 
among which boric acid was included. Initial screening experiments in acetonitrile afforded a vinpocetine boric acid ionic cocrystal (1) in $85 \%$ yield. Conversely, grinding and slurry were not successful in cocrystal formation.

Solid-state characterizations including X-ray diffraction, SSNMR and DSC were performed on 1.

\section{X-Ray Diffraction}

Single crystal X-ray diffraction (Figure 2 ) showed that $\mathbf{1}$ crystallizes in the monoclinic $P 2_{1}$ space group with two independent vinpocetine molecules per asymmetric unit. The bond distance and residual electron density analysis suggests that the amine function on the two molecules (N11c and N11d) are different, one being neutral and the other being protonated. Indeed the neutral amine acts as an H-bond acceptor for a boronic acid ( $\mathrm{N} \cdots \mathrm{O}$ distance ca. $2.72 \AA$ ) while the protonated one is the $\mathrm{H}$-bond donor for a charged assisted interaction with a $\mathrm{B}_{5} \mathrm{H}_{4} \mathrm{O}_{10}$ anion (N...O distance ca. $2.81 \AA$ ). The anion and boronic acid interact further via an $\mathrm{OH} \cdots \mathrm{OH} \mathrm{H}$-bond dimer $\left(R_{2}^{2}(8)\right.$ in graph set notation). These supramolecular units containing inorganic and organic components form alternating layers that align parallel to the ab plane, as shown in Figure 2. The experimental PXRD pattern of 1 is reported in Figure 3 and showed a series of sharp diffraction peaks in the $2 \theta$ theta range $5-40^{\circ}$, suggesting the high crystalline nature of the powdered sample. From Figure 3 it can be also noticed that the experimental PXRD and the calculated patterns of 1 are very similar, indicating absence of significant amounts of impurities.

It must be noted that although the $\mathrm{B}_{5} \mathrm{H}_{4} \mathrm{O}_{10}$ anion is a rather common species reported in over 150 structures in the $\mathrm{CSD}$, only in 8 entries the anion co-crystallizes with $\mathrm{B}(\mathrm{OH})_{3}$.

\section{Differential Scanning Calorimetry}


The solid-state thermal behavior of pure vinpocetine, pure boric acid and $\mathbf{1}$ was investigated by means of DSC analysis. The DSC curve of pure boric acid shows two endothermal events (Figure 4), the first being the melt occurring at $148{ }^{\circ} \mathrm{C}$ followed by a second slightly sharper endothermal event at $159{ }^{\circ} \mathrm{C}$, possibly due to the loss of water molecules and crystal lattice transformations of the initial boric acid into other forms more stable at higher temperatures. ${ }^{36}$ Pure vinpocetine shows a single sharp melting peak at $152{ }^{\circ} \mathrm{C}$, indicating the highly crystalline nature of the sample. Vinpocetine starts to decompose after ca. $200{ }^{\circ} \mathrm{C}$ (Figure 4). 1 showed a large melting event with a peak at $191^{\circ} \mathrm{C}$, which is higher than both pure vinpocetine and boric acid. The broad melting event in the cocrystal, in accordance to some peak broadening showed in experimental PXRD pattern, is possibly due to the different interactions of vinpocetine molecules within the cocrystal lattice (hydrogen-bonded and protonated vinpocetine molecules), a large range of particle size or a less crystalline sample.

\section{Solid-state NMR spectroscopy}

The SSNMR characterization can facilitate the determination of the moieties present in the crystal structure, in particular in addressing the question of whether the compound discussed herein should be regarded as a molecular cocrystal or as an ionic cocrystal. The difference is subtle since it depends on the hydrogen position along the $\mathrm{O} \cdots \mathrm{H} \cdots \mathrm{N}$ interaction, i.e. whether it is close to oxygen or to nitrogen. This depends on several factors including the relative values of pKa (but pKa can be misleading as it is evaluated with respect to the solvent, usually water, and does not necessarily correlate in the solid-state) $)^{37,38}$ the crystal packing and the temperature. It has been reported that NMR spectroscopic methods, such as the measurement of ${ }^{13} \mathrm{C}$ chemical shifts of carboxylic carbon atoms, are good indicators of the protonated state of $\mathrm{COOH}$ groups ${ }^{39-41}$. On

the other hand, the ${ }^{15} \mathrm{~N}$ chemical shift is remarkably sensitive to the protonation degree of $\mathrm{H}$ - 
bonded nitrogen atom with shifts at higher or lower frequencies accordingly with the type of nitrogen atom, i.e. whether aromatic or aliphatic ${ }^{42-47}$. Similar effects are observed upon halogen bond formation or metal coordination ${ }^{48-53}$ which is in agreement with the minor contribution of the lone pair to $\sigma^{\mathrm{p}}$ loc removed by quaternization ${ }^{54-56}$. The ${ }^{13} \mathrm{C}$ and ${ }^{15} \mathrm{~N}$ chemical shifts with assignment are reported in Tables 1 and 2, respectively. The ${ }^{13} \mathrm{C}$ and ${ }^{15} \mathrm{~N}$ CPMAS spectra are reported in Figures 5 and 6, respectively. ${ }^{13} \mathrm{C}$ spectral editing experiments (Spectra reported in the Supporting information Figure S1) were fundamental for the correct assignment of the resonances. For atom numbers we refer to Figure 1: suffix "d" to the number indicates the charged molecule while suffix "a" the neutral one.

The ${ }^{13} \mathrm{C}$ CPMAS spectra of pure vinpocetine and $\mathbf{1}$ (Figure 5) can be divided in three main regions: $\mathrm{CH}_{2}, \mathrm{CH}$ and $\mathrm{C}_{\mathrm{q}}$ aliphatic carbons (6-63 ppm), $\mathrm{sp}^{2} \mathrm{CH}$ and $\mathrm{C}_{\mathrm{q}}$ carbons (107-134 ppm) and CO carbons (161-164 ppm). The spectrum of $\mathbf{1}$ is characterized by sharp peaks (FWHM around $50-70 \mathrm{~Hz}$ ) highlighting the high crystallinity of the sample. Furthermore, the splitting of almost all resonances in the spectrum of $\mathbf{1}$ is in agreement with the presence of two independent molecules in the unit cell $\left(Z^{\prime}=2\right)$. The ${ }^{15} \mathrm{~N}$ CPMAS spectrum of pure vinpocetine (Figure 6a) presents two resonances at 4.1 and $113.6 \mathrm{ppm}$ for N11 and N1, respectively both attributed to nitrogen atoms not involved in any interaction. On the other hand, the ${ }^{15} \mathrm{~N}$ CPMAS spectrum of $\mathbf{1}$ (Figure 6b) shows two signals for the N11 atom at higher frequencies (10.1 and $18.7 \mathrm{ppm}$ ) with respect to the pure vinpocetine signal. The former, attributed to N11c, is typical of a nitrogen involved in $\mathrm{N} \cdots \mathrm{H}-\mathrm{O}$ H-bond while the latter, assigned to $\mathrm{N} 11 \mathrm{~d}$, is characteristic of a $\mathrm{N}^{+}-\mathrm{H} \cdots \mathrm{O}^{-}$ interaction. This is a clear indication that a proton transfer took place from the $\mathrm{B}_{5} \mathrm{H}_{4} \mathrm{O}_{10}$ anion to vinpocetine and that there is concomitant presence of both a neutral molecule and a salt in the 
unit cell. No significant shifts were observed for the N1 atom on passing from pure vinpocetine to the cocrystal in agreement with the small rearrangement experienced.

\section{Powder Dissolution Test}

Powder dissolution tests (PDTs) were performed for pure vinpocetine and 1. Pure vinpocetine showed a dissolution profile typical of a poorly soluble drug where concentration of $0.8 \mathrm{mg} / \mathrm{L}$ was reached after $5 \mathrm{~h}$ (Figure 7). Conversely, in 1 a significant improvement of vinpocetine dissolution rate was achieved. Compared to the orginal drug, the dissolution behavior of vinpocetine in $\mathbf{1}$ appears to be superior both in terms of rate and extent of total drug dissolved during the first 5 hours. 1 reaches a concentration of $1.4 \mathrm{mg} / \mathrm{L}$; near to the value for pure vinpocetine Cs, $1.6 \mathrm{mg} / \mathrm{L}$ (Figure 7). It is worth noting that the Cs value for pure vinpocetine was reached after 24 hours of dissolution analysis (using the same experimental conditions as the powder dissolution analyses), and is consistent with other values previously reported in literature. $^{31}$ The fact that $\mathbf{1}$ dissolves at a much faster rate than vinpocetine is promising and a faster in vivo absorption is expected. In this case the innovative approach of an ionic cocrystallization permits a great improvement of solubilization kinetics with respect to pure crystalline vinpocetine, which can be attributed to different lattice and solvation energies.

\section{In Vivo absorption studies}

Inspired by these promising in vitro dissolution profiles, an in vivo pilot study in humans was carried out. A single oral dose of pure vinpocetine was administered to six male volunteers. Following a one week wash out period, the volunteers were then dosed with 1. The plasma profiles are presented in Figure 8 whilst the pharmacokinetic parameters are listed in Table 3. 
Our results demonstrate an increase in apovincaminic acid concentration corresponding to improved vinpocetine absorption. In fact, it appears that $\mathbf{1}$ is more rapidly absorbed, showing a shorter $\mathrm{t}_{1 / 2 \mathrm{Ka}}$ and $\mathrm{t}_{\max }$, and higher $\mathrm{C}_{\max }$. In addition to the increased absorption rate, we observed approximately 2 -fold improvement in the extent of vinpocetine absorption (Frel). Collectively, these results demonstrate that the improved solubilization kinetics is reflected in an enhanced bioavailability. $^{57}$

\section{CONCLUSIONS}

In summary, we report herein the first ionic cocrystal of vinpocetine, an active ingredient indicated for the improvement of cerebral circulation. As an ionic cocrystal, vinpocetine showed significantly improved dissolution performance with respect to pure vinpocetine. Additionally, the results obtained from the pilot human pharmacokinetic study reveal that the oral bioavailability of vinpocetine is doubled when administered as $\mathbf{1}$. This study suggests that cocrystallization can be a potential solution to the solubility and bioavailability problems that have thwarted the development of vinpocetine as an effective treatment option for its numerous potential clinical indications. Moreover, these results further verify that cocrystallization is a promising methodology for achieving the desired physicochemical properties of a compound in humans and that these improvements can lead to enhanced bioavailability when applied to compounds that are limited by their solubility.

\section{ACKNOWLEDGMENTS}


The authors thank "Università degli Studi di Trieste - Finanziamento di Ateneo per progetti di Ricerca Scientifica - FRA 2015” for funding.

\section{NOTES:}

†Crystallographic Information File for 1 is available from CCDC: ref. number 1498771.

Crystal data 1: colourless plate, $0.200 \times 0.100 \times 0.100 \mathrm{~mm}^{3}$. Sum Formula $\mathrm{C}_{44} \mathrm{H}_{60} \mathrm{~B}_{6} \mathrm{~N}_{4} \mathrm{O}_{17}, M=$ 981.82, crystal system monoclinic, $P 2_{1}$ space group (No. 4), $V=2428.2(3) \AA^{3}, Z=2, D_{c}=1.343$ $\mathrm{g} / \mathrm{cm}^{3}, F_{000}=1036$, Bruker Quest, MoK $\alpha$ radiation, $\lambda=0.71073 \AA, T=100(2) \mathrm{K}, 2 \theta_{\max }=55.3^{\circ}$, 29882 reflections collected, 11136 unique $\left(\mathrm{R}_{\mathrm{int}}=0.0494\right)$. Final $G o o F=1.021, R_{1}=0.0502, w R_{2}$ $=0.0821, R$ indices based on 8152 reflections with $\mathrm{I}>2(\mathrm{I})\left(\right.$ refinement on $F^{2}$ ), 652 parameters, 1

restraint. Lp and absorption corrections applied, $\mu=0.100 \mathrm{~mm}^{-1}$. Absolute structure parameter $=$ $0.2(4)$.

\section{REFERENCES}

1. Allen LV, Popovich NG, Ansel HC. 2005. Ansel's pharmaceutical dosage forms and drug delivery systems. Baltimore, Maryland: Lippincott Williams and Wilkins.

2. Haleblian J, McCrone W. 1969. Pharmaceutical applications of polymorphism. J Pharm Sci 58:911-929.

3. Berge SM, Bighley LD, Monkhous DC. 1977. Pharmaceutical salts. J Pharm Sci 66:1-19. 
4. Vishweshwar P, McMahon JA, Bis JA, Zaworotko MJ. 2006. Pharmaceutical co-crystals. J Pharm Sci 95:499-516.

5. Schultheiss N, Newman A. 2009. Pharmaceutical cocrystals and their physicochemical properties. Cryst Growth Des 9:2950-2967.

6. Shan N, Zaworotko MJ. 2008. The role of cocrystals in pharmaceutical science. Drug Discovery Today 13:440-446.

7. Aaker"oy CB, Forbes S, Desper J. 2009. Using cocrystals to systematically modulate aqueous solubility and melting behavior of an anticancer drug. J Am Chem Soc 131:1704817049.

8. Childs SL, Chyall LJ, Dunlap JT, Smolenskaya VN, Stahly BC, Stahly GP. 2004. Crystal engineering approach to forming cocrystals of amine hydrochlorides with organic acids. Molecular complexes of fluoxetine hydrochloride with benzoic, succinic, and fumaric acids. J Am Chem Soc 126:13335-13342.

9. Remenar JF, Morissette SL, Peterson ML, Moulton B, MacPhee JM, Guzman HR, Almarsson O* . 2003. Crystal engineering of novel cocrystals of a triazole drug with 1,4dicarboxylic acids. J Am Chem Soc 125:8456-8457

10. Aitipamula S, Banerjee R, Cheney ML, Zaworotko M. 2012. Polymorphs, salts and Cocrystals: What?s in a Name?. Cryst. Growth Des.,, 12, 2147-2152.

11. Almarsson O*, Zaworotko MJ. 2004. Crystal engineering of the composition of pharmaceutical phases. Do pharmaceutical cocrystals represent a new path to improve medicines? Chem Commun 1889-1896.

12. Remenar JF, Peterson ML, Stephens PW, Zhang Z, Zimenkov Y, Hickey MB. 2007. Celecoxib:Nicotinamide dissociation: using excipients to capture the cocrystal's potential. Mol Pharm 4:386-400.

13. Good DJ, Rodriguez-Hornedo N. 2009. Solubility advantage of pharmaceutical cocrystals. Cryst Growth Des 9:2252-2264. 
14. Karki S, Friscic T, Fabian L, Laity PR, Day GM, Jones W. 2009. Improving mechanical properties of crystalline solids by cocrystal formation: new compressible forms of paracetamol. Adv Mater 21:3905-3909.

15. Trask AV, Motherwell WDS, Jones W. 2005. Pharmaceutical cocrystallization: engineering a remedy for caffeine hydration. Cryst Growth Des 5:1013-1021.

16. McNamara DP, Childs SL, Giordano J, Iarriccio A, Cassidy J, Shet MS, Mannion R, O’Donnell E, Park A. 2006. Use of a glutaric acid cocrystal to improve oral bioavailability of a low solubility API. Pharm Res 23:1888-1897.

17. Desiraju GR. 1989. Crystal Engineering. The design of organic solids. Elsevier, Amsterdam.

18. Desiraju GR. 1995. Supramolecular synthons in crystal engineering- a new organicsynthesis. Angewandte Chemie 34:2311-2327.

19. Cheney ML, Shan N, Healey ER, Hanna M, Wojtas L, Zaworotko MJ, Sava V, Song S, Sanchez-Ramos JR. 2010. Effects of crystal form on solubility and pharmacokinetics: a crystal engineering case study of lamotrigine. Cryst Growth Des 10:394-405.

20. Allen FH. 2002. The Cambridge Structural Database: a quarter of a million crystal structures and rising. Acta Crystallogr Sect B-Struct Sci 58:380-388.

21. Stanton MK, Bak A. 2008. Physicochemical properties of pharmaceutical co-crystals: a case study of ten AMG 517 cocrystals. Cryst Growth Des 8:3856-3862.

22. Braga D, Grepioni F, Maini L, Prosperi S, Gobetto R, Chierotti MR. 2010. From unexpected reactions to a new family of ionic co-crystals: the case of barbituric acid with alkali bromides and caesium iodide. Chem. Commun. 46: 7715-7717.

23. Duggirala NK, Perry LM, Almarsson O, Zaworotko MJ. 2016. Pharmaceutical cocrystals: along the path to improved Medicines Chem Commun., 52: 640-655. 
24. Bencsath P, Debrczeni L, Takács L. 1976. Effect of ethyl apovincaminate on cerebral circulation of dogs under normal conditions and in arterial hypoxia. Arzneim-Forsch/Drug Res 26:1920-3.

25. Luo Y, Chen D, Ren L, Zhao X, Qin J. 2006. Solid lipid nanoparticles for enhancing Vinpocetine's oral bioavailability. J Control Release 114:53-9.

26. Csanda E, Harcos P, Bacsy Z, Berghammer R, Kenez J. 1988. Ten years of experience with Cavinton. Drug Dev Res 14:185-7.

27. Grandt R, Beitinger R, Schateltenbrand R, Braun W. 1989. Vinpocetine pharmacokinetics in elderly subjects. Arzneim-Forsch/Drug Res 39:1599-602.

28. Szakacs T, Veres Z, Vereczkey L. 2001. In vitro-in vivo correlation of the pharmacokinetics of Vinpocetine. Pol J Pharmacol. 53:623-8.

29. BrukerSMART, SAINT-Plus, SADABS, XP and SHELXTL.1997. Madison, Wisconsin.

30. Sheldrick GM. 1997. SHELXTL. Gottingen, Germany: University of Gottingen.

31. Ribeiro L, Falcao AC, Patricio JAB, Ferreira DC, Veiga FJB. 2007. Cyclodextrin multicomponent complexation and controlled release delivery strategies to optimize the oral bioavalaibility of Vinpocetine. J Pharm Sci 96:2018-2028.

32. Sun DD, Ju TR, Lee PI. 2012. Enhanced kinetic solubility profiles of indomethacin amorphous solid dispersions in poly(2-hydroxyethyl methacrylate) hydrogels, Eur. J. Pharm. Biopharm. 81 149-158.

33. Hasa D, Voinovich D, Perissutti B, Bonifacio A, Grassi M, Franceschinis E, Dall'Acqua S, Speh M, Plavec J, Invernizzi S. 2011. Multidisciplinary Approach on Characterizing a Mechanochemically Actived Composite of Vinpocetine and Crospovidone. J Pharm Sci 100:915-932. 
34. Vlase L, Bodiu B, Leucuta SE. Pharmacokinetics and comparative bioavailability of two Vinpocetine tablet formulations in healthy volunteers by using the metabolite Apovincaminic acid as pharmacokinetic parameter. Arzneim-Forsch/Drug Res. 2005;55:664-8.

35. D'Argenio, D.Z., A. Schumitzky and X. Wang. ADAPT 5 User's Guide: Pharmacokinetic/Pharmacodynamic Systems Analysis Software. Biomedical Simulations Resource, Los Angeles, 2009.

36. Sevim F, Demir F, Bilen M, Okur H. 2006. Kinetic analysis of thermal decomposition of boric acid from thermogravimetric data. Korean J. Chem. Eng. 23(5) 736-740

37. Gale PA, Steed J. 2012. Supramolecular Chemistry From Molecules to Nanomaterials. Wiley: Chichester, UK, Vol. 6: 2829-2867.

38. Cruz-Cabeza AJ. 2012. Acid-Base crystalline complexes and the pKa rule. CrystEngComm. 14: 6362-6365.

39. Gu Z, McDermott A, 1993. Chemical shielding anisotropy of protonated and deprotonated carboxylates in amino acids. J. Am. Chem. Soc. 115: 4282-4285.

40. Naito A, Ganapathy S, Akasaka S, McDowell CJ. 1981. Chemical shielding tensor and ${ }^{13} \mathrm{C}-$ ${ }^{14} \mathrm{~N}$ dipolar splitting in single crystals of L-alanine. J. Chem. Phys. 74: 3190-3198.

41. Braga D, Maini L, De Sanctis G, Rubini K, Grepioni F, Chierotti MR, Gobetto R. 2003. Mechanochemical Preparation of Hydrogen-Bonded Adducts Between the Diamine 1,4Diazabicyclo[2.2.2]octane and Dicarboxylic Acids of Variable Chain Length: An X-ray Diffraction and Solid-State NMR Study. Chem. Eur. J. 9: 5538-5548.

42. Gobetto R, Nervi C, Valfre E, Chierotti MR, Braga D, Maini L, Grepioni F, Harris RK, Ghi PY. 2005. ${ }^{1} \mathrm{H}$ MAS, ${ }^{15} \mathrm{~N}$ CPMAS, and DFT Investigation of Hydrogen-Bonded Supramolecular Adducts between the Diamine 1,4-Diazabicyclo-[2.2.2]octane and Dicarboxylic Acids of Variable Chain Length. Chem. Mater. 17: 1457-1466.

43. Diez-Pena E, Quijada-Garrido I, Barrales-Rienda JM, Schnell I, Spiess HW. 2004. Advanced ${ }^{1} \mathrm{H}$ solid-state NMR spectroscopy on hydrogels, 1 -The effect of hydrogen bonding in the 
collapse of poly(methacrylic acid) (PMAA) hydrogels. Macromol. Chem. Phys. 205: 430437.

44. Braga D, Grepioni F, Polito M, Chierotti MR, Ellena S, Gobetto R. 2006. A Solid-Gas Route to Polymorph Conversion in Crystalline $\left[\mathrm{FeII}\left(\eta^{5}-\mathrm{C}_{5} \mathrm{H}_{4} \mathrm{COOH}\right)_{2}\right]$. A Diffraction and SolidState NMR Study. Organometallics 25: 4627-4633.

45. Gobetto R, Nervi C, Chierotti MR, Braga D, Maini L, Grepioni F, Harris RK, Hodgkinson RP. 2005. Hydrogen Bonding and Dynamic Behaviour in Crystals and Polymorphs of Dicarboxylic-Diamine Adducts: A Comparison between NMR Parameters and X-ray Diffraction Studies. Chem. Eur. J. 11: 7461-7471.

46. Tatton AS, Pham TN, Vogt FG, Iuga D, Edwards AJ, Brown S.P. 2013. Probing hydrogen bonding in cocrystals and amorphous dispersions using (14)N-1H HMQC solid-state NMR. Mol. Pharmacol. 10: 999-1007.

47. Braga D, Chelazzi L, Grepioni F, Dichiarante E, Chierotti MR, Gobetto R. 2013. Molecular Salts of Anesthetic Lidocaine with Dicarboxylic Acids: Solid-State Properties and a Combined Structural and Spectroscopic Study. Cryst. Growth Des. 13: 2564-2572.

48. Baldrighi M, Bartesaghi D, Cavallo G, Chierotti MR, Gobetto R, Metrangolo P, Pilati T, Resnati G, Terraneo G. 2014. Polymorphs and co-crystals of haloprogin: an antifungal agent. CrystEngComm 16: 5897-5904.

49. Baldrighi M, Bartesaghi D, Cavallo G, Chierotti MR, Gobetto R, Metrangolo P, Pilati T, Resnati G, Terraneo G. 2013. Halogen Bonding and Pharmaceutical Cocrystals: The Case of a Widely Used Preservative. Mol. Pharmaceutics 10: 1760-1772.

50. Bolje A, Hohloch S, Urankar D, Pevec A, Gazvoda M, Sarkar B, Košmrlj J. 2014. Exploring the scope of pyridyl-and picolyl-functionalized 1, 2, 3-triazol-5-ylidenes in bidentate coordination to ruthenium (II) cymene chloride complexes. Organometallics 33: 2588-2598.

51. Soria L, Ovejero P, Cano M, Heras VJ, Torres MR, Claramunt R, Cornago P. 2014. Coordination behaviour of new dipyridylpyrazole ligands towards $\mathrm{ZnCl}_{2}$ and $\mathrm{PdCl}_{2}$ 
fragments. Crystalline structural characterization and multinuclear NMR studies as evidence of linkage and conformational isomers. RSC Advances 4: 9383-9394.

52. Pettinari R, Pettinari C, Marchetti F, Gobetto R, Nervi C, Chierotti MR, Chan EJ, Skelton BW, White AH. 2010. Solid-State ${ }^{15}$ N CPMAS NMR and Computational Analysis of Ligand Hapticity in Rhodium(n-diene) Poly(pyrazolyl)borate Complexes. Inorg. Chem. 49: 1120511215.

53. Chierotti MR, Gobetto R. 2009. Solid-State NMR Investigation of Ligand Mobility and Reactivity in Transition Metal Complexes. Eur. J. Inorg. Chem. 2581-2597.

54. Levy GC, Lichter RL. 1979. "Nitrogen-15 Nuclear Magnetic Resonance Spectroscopy", John Wiley \& Sons, Inc., New York.

55. Chierotti MR, Gobetto R. 2008. Solid-state NMR studies of weak interactions in supramolecular systems. Chem. Commun. 1621-1634.

56. Toebbens DM, Glinneman J, Chierotti MR, van de Streek J, Sheptyakov D. 2012. On the high-temperature phase of barbituric acid. Cryst. Eng. Comm. 14: 3046-3055.

57. Shan N, Perry ML, Weyna DR, Zaworotko MJ. 2014. Impact of pharmaceutical cocrystals: the effects on drug pharmacokinetics. Expert Opin. Drug Metab. Toxicol. 10:1255-1271. 
Table $1 .{ }^{13} \mathrm{C}$ chemical shifts with assignment of pure vinpocetine and $\mathbf{1}$.

\begin{tabular}{|c|c|c|c|}
\hline Atom & Type & Vinpocetine & 1 \\
\hline \multirow[t]{2}{*}{20} & $\mathrm{C}_{\mathrm{q}}$ & 164.1 & 161.9 \\
\hline & & & 161.2 \\
\hline \multirow[t]{2}{*}{2} & $\mathrm{C}_{\mathrm{q}}$ & 133.7 & 135.7 \\
\hline & & & 133.9 \\
\hline 17 & $\mathrm{C}_{\mathrm{q}}$ & 132.4 & 129.0 \\
\hline $7 / 18$ & $\mathrm{C}_{\mathrm{q}} / \mathrm{CH}$ & 128.8 & 129.0 \\
\hline 19 & $\mathrm{C}_{\mathrm{q}}$ & 127.7 & 129.0 \\
\hline \multirow[t]{2}{*}{5} & $\mathrm{CH}$ & 123.1 & 124.6 \\
\hline & & & 122.4 \\
\hline 6 & $\mathrm{CH}$ & 120.6 & 121.6 \\
\hline \multirow[t]{2}{*}{4} & $\mathrm{CH}$ & 118.9 & 120.2 \\
\hline & & & 117.9 \\
\hline \multirow[t]{2}{*}{3} & $\mathrm{CH}$ & 112.8 & 113.7 \\
\hline & & & 112.1 \\
\hline \multirow[t]{2}{*}{8} & $\mathrm{C}_{\mathrm{q}}$ & 107.9 & 110.2 \\
\hline & & & 109.2 \\
\hline \multirow[t]{2}{*}{22} & $\mathrm{CH}_{2}$ & 63.5 & 62.5 \\
\hline & & & 61.3 \\
\hline \multirow[t]{2}{*}{16} & $\mathrm{CH}$ & 58.6 & 55.6 \\
\hline & & & 51.9 \\
\hline \multirow[t]{2}{*}{10} & $\mathrm{CH}_{2}$ & 51.0 & 51.9 \\
\hline & & & 49.8 \\
\hline \multirow[t]{2}{*}{12} & $\mathrm{CH}_{2}$ & 44.7 & 44.9 \\
\hline & & & 43.6 \\
\hline \multirow[t]{2}{*}{15} & $\mathrm{C}_{\mathrm{q}}$ & 37.9 & 39.1 \\
\hline & & & 37.9 \\
\hline \multirow[t]{2}{*}{14} & $\mathrm{CH}_{2}$ & 27.3 & 32.1 \\
\hline & & & 28.6 \\
\hline \multirow[t]{2}{*}{25} & $\mathrm{CH}_{2}$ & 25.9 & 28.6 \\
\hline & & & 25.6 \\
\hline \multirow[t]{2}{*}{9} & $\mathrm{CH}_{2}$ & 20.8 & 20.4 \\
\hline & & & 17.5 \\
\hline \multirow[t]{2}{*}{13} & $\mathrm{CH}_{2}$ & 16.4 & 16.6 \\
\hline & & & 16.0 \\
\hline \multirow[t]{2}{*}{23} & $\mathrm{CH}_{3}$ & 14.0 & 15.0 \\
\hline & & & 11.9 \\
\hline \multirow[t]{2}{*}{26} & $\mathrm{CH}_{3}$ & 6.7 & 11.3 \\
\hline & & & 7.0 \\
\hline
\end{tabular}


Table 2. ${ }^{15} \mathrm{~N}$ chemical shifts with assignment of pure vinpocetine and $\mathbf{1}$.

\begin{tabular}{lcccc}
\hline Atom & Vinpocetine & note & $\mathbf{1}$ & note \\
\hline N1 & 113.6 & Free N & & \\
N11 & 4.1 & Free N & & \\
N1c/d & & & $110.9 / 112.7$ & Free N \\
N11c & & & 10.1 & N $\cdots$ H-O \\
N11d & & & 18.7 & $\mathrm{~N}^{+}-\mathrm{H}_{\cdots} \mathrm{O}^{-}$ \\
\hline
\end{tabular}




\section{FIGURE LEGENDS}

Figure 1. Structure of vinpocetine with atom numbering scheme.

Figure 2. Crystal structure of $\mathbf{1}$ obtained from Single crystal X-ray diffraction.

Figure 1. Structure of vinpocetine with atom numbering scheme.

Figure 2. Crystal structure of $\mathbf{1}$ obtained from Single crystal X-ray diffraction

Figure 3. Profiles of experimental powder X-ray diffractogram of $\mathbf{1}$ and the calculated diffractogram of $\mathbf{1}$ based on the single crystal X-ray diffraction data.

Figure 4. DCS curves of $\mathbf{1}$, boric acid and vinpocetine.

Figure 5. ${ }^{13} \mathrm{C}(100.64 \mathrm{MHz})$ CPMAS spectra with assignment of (a) pure vinpocetine and (b) $\mathbf{1}$, recorded with a spinning speed of $12 \mathrm{kHz}$.

Figure 6. ${ }^{15} \mathrm{~N}(40.56 \mathrm{MHz})$ CPMAS spectra with relevant assignments of (a) pure vinpocetine and (b) 1, recorded with a spinning speed of $9 \mathrm{kHz}$. Suffix "c" or "d" in the atom number indicates the neutral and charged independent vinpocetine molecule, respectively.

Figure 7. Dissolution profile (in $\mathrm{pH} 7.4$ phosphate buffer) of $\mathbf{1}$ and vinpocetine compared to vinpocetine's solubility at equilibrium $(\mathrm{Cs}$, equilibration time $=24 \mathrm{~h})$

Figure 8. Plasma concentrations of Apovincaminic acid following the oral administration of cocrystal $\mathbf{1}(\boldsymbol{\triangle})$ and pure vinpocetine $(\mathbf{(})$.

Figure S1. ${ }^{13} \mathrm{C}$ (100.64 MHz) CPPISPI spectral editing experiment with chemical shifts of (a) pure vinpocetine and (b) 1 recorded with a spinning speed of $12 \mathrm{kHz}$. 

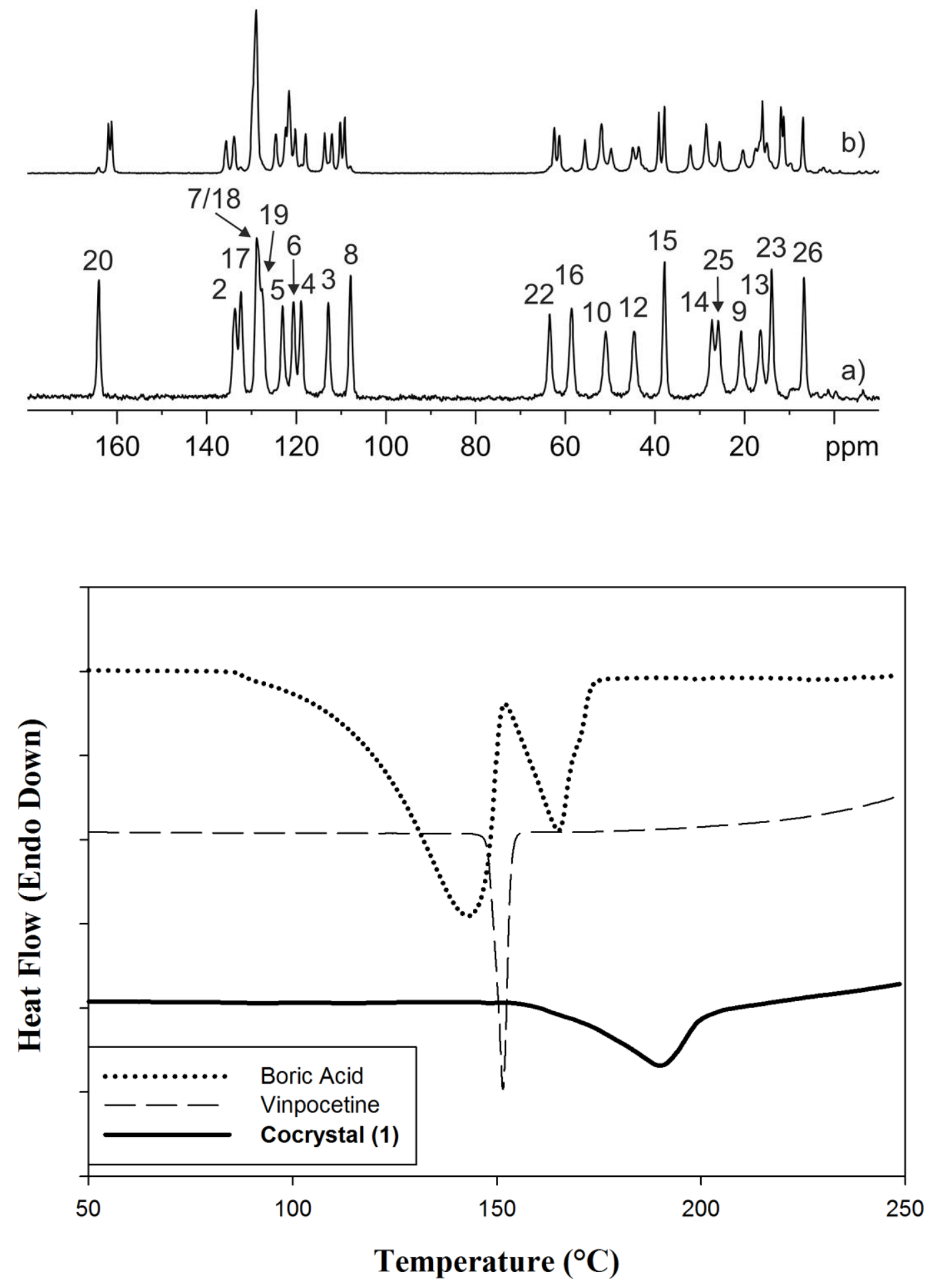


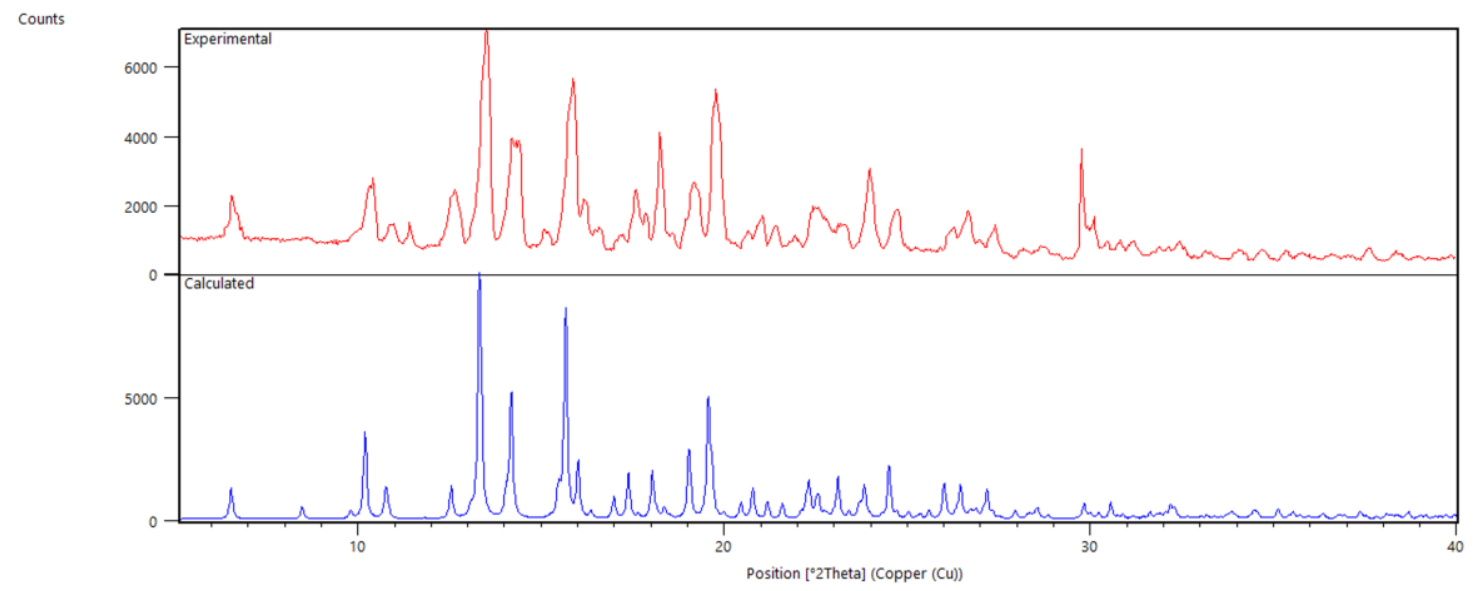



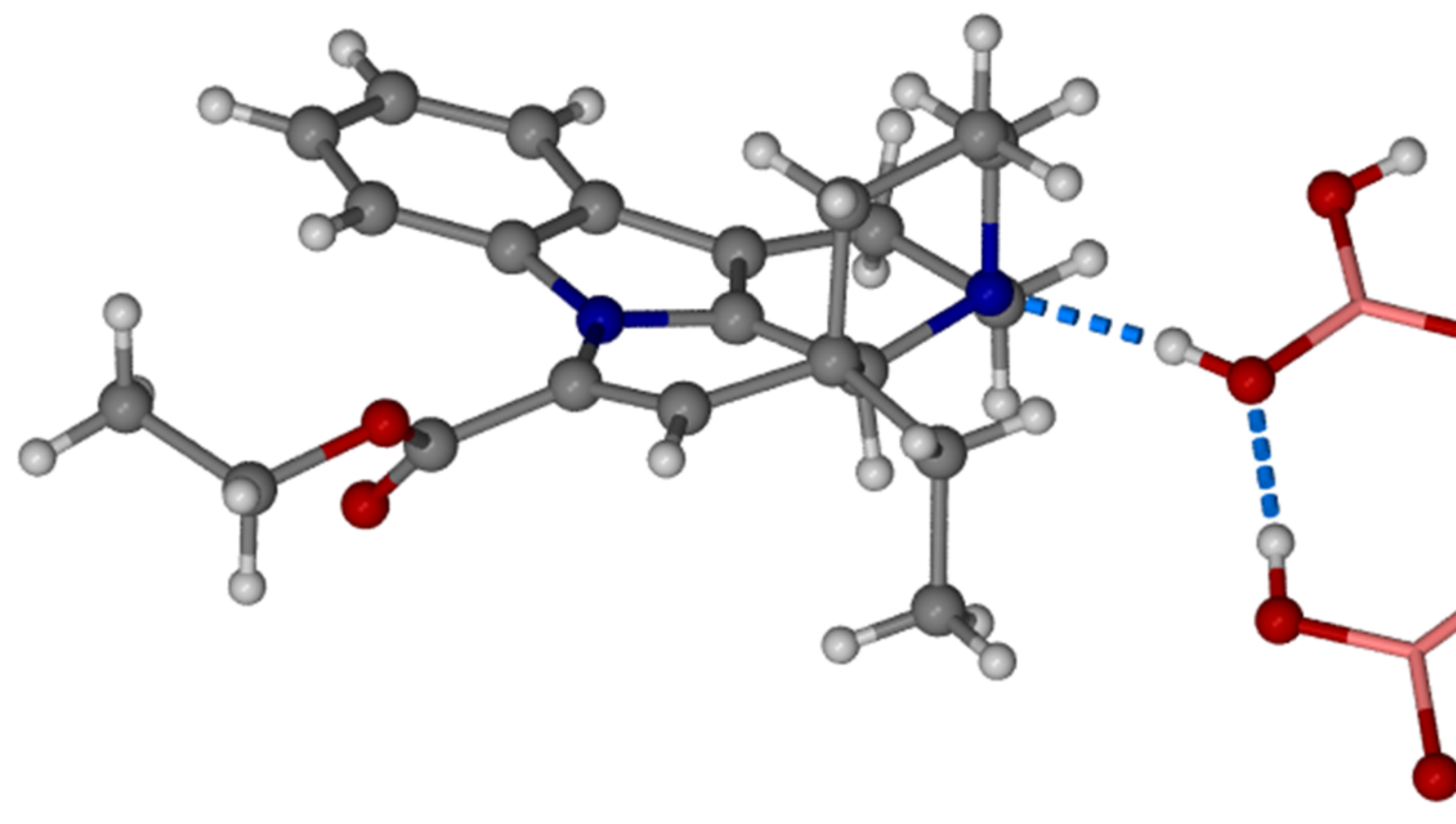

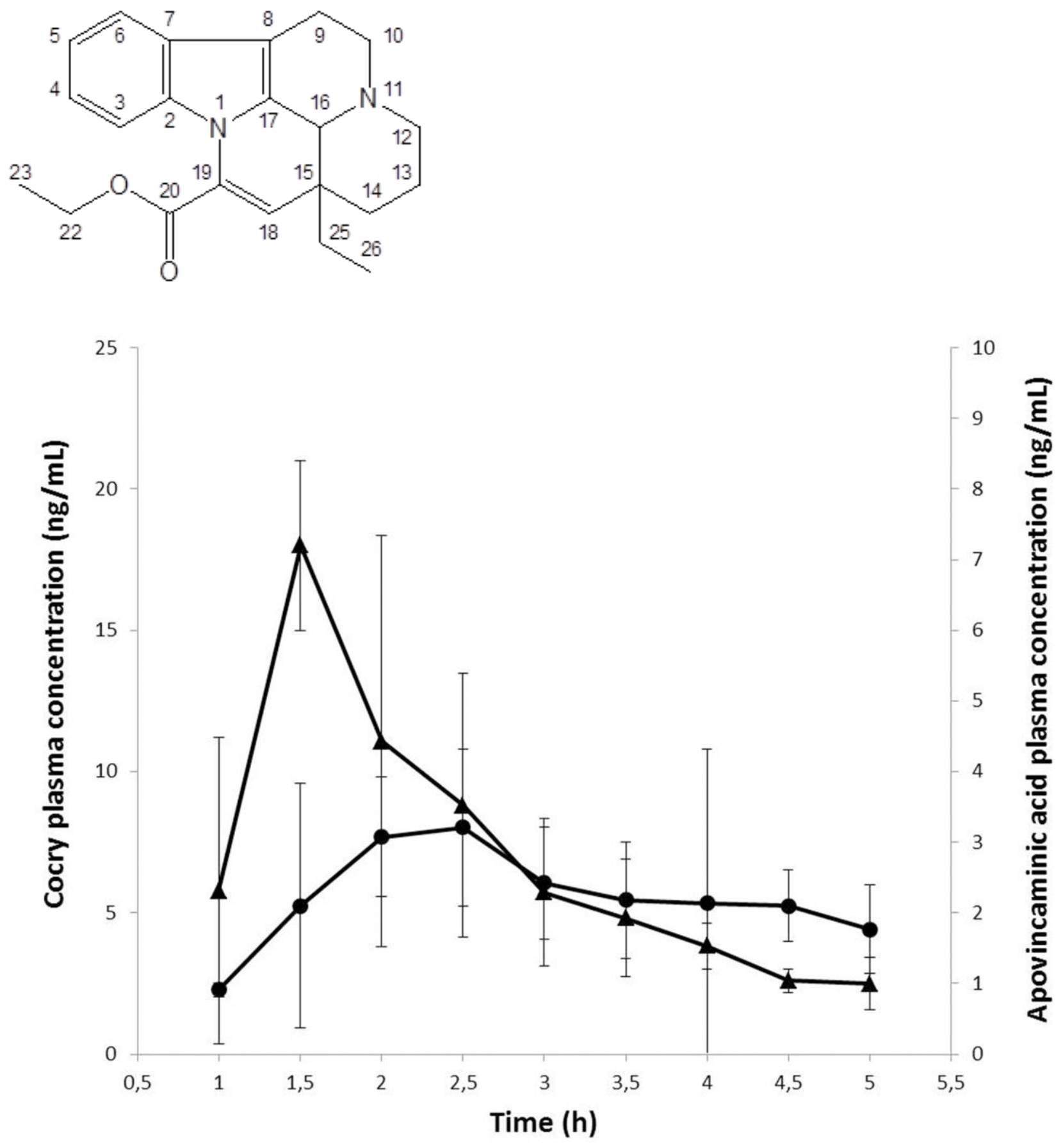


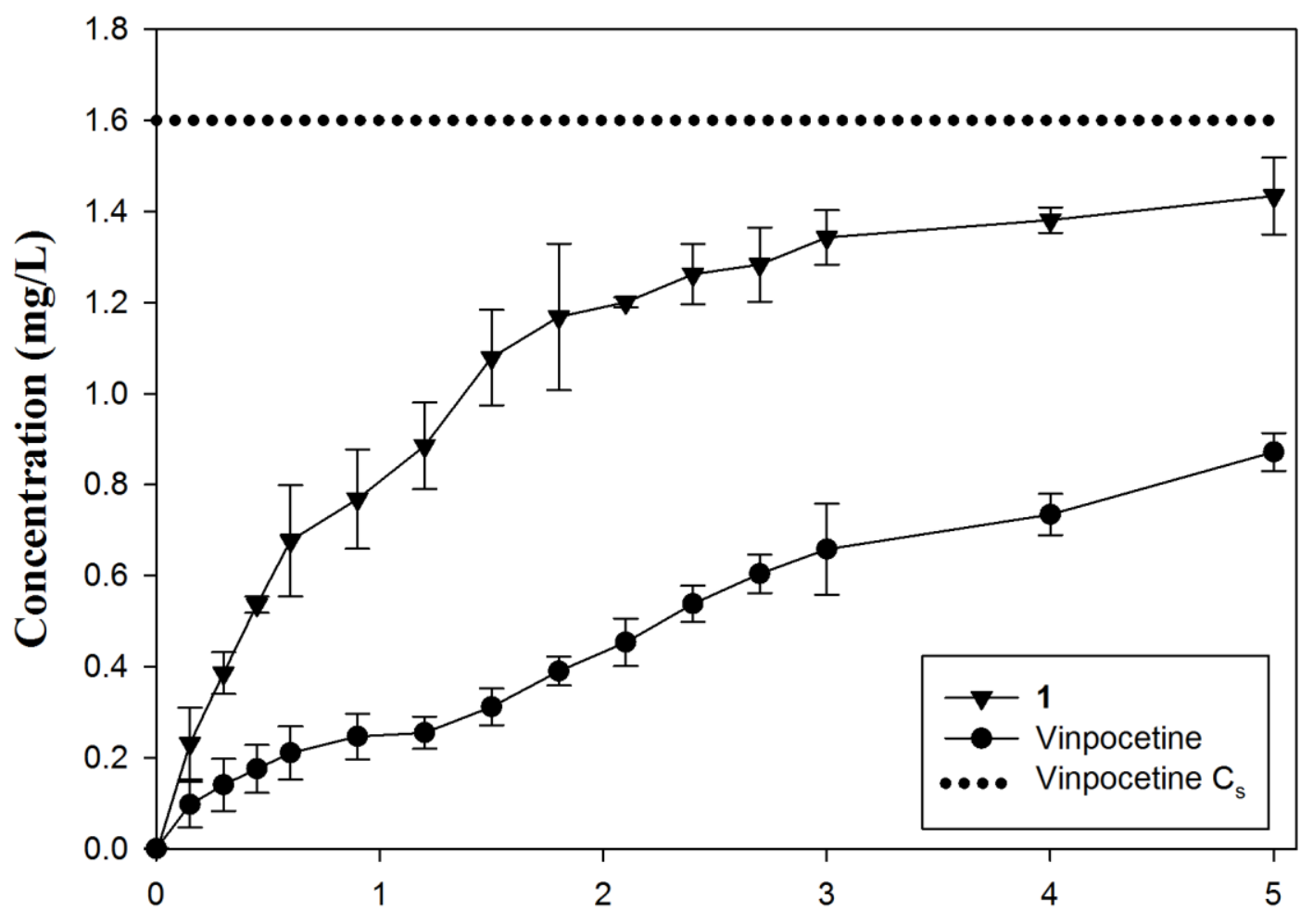

Time (h)

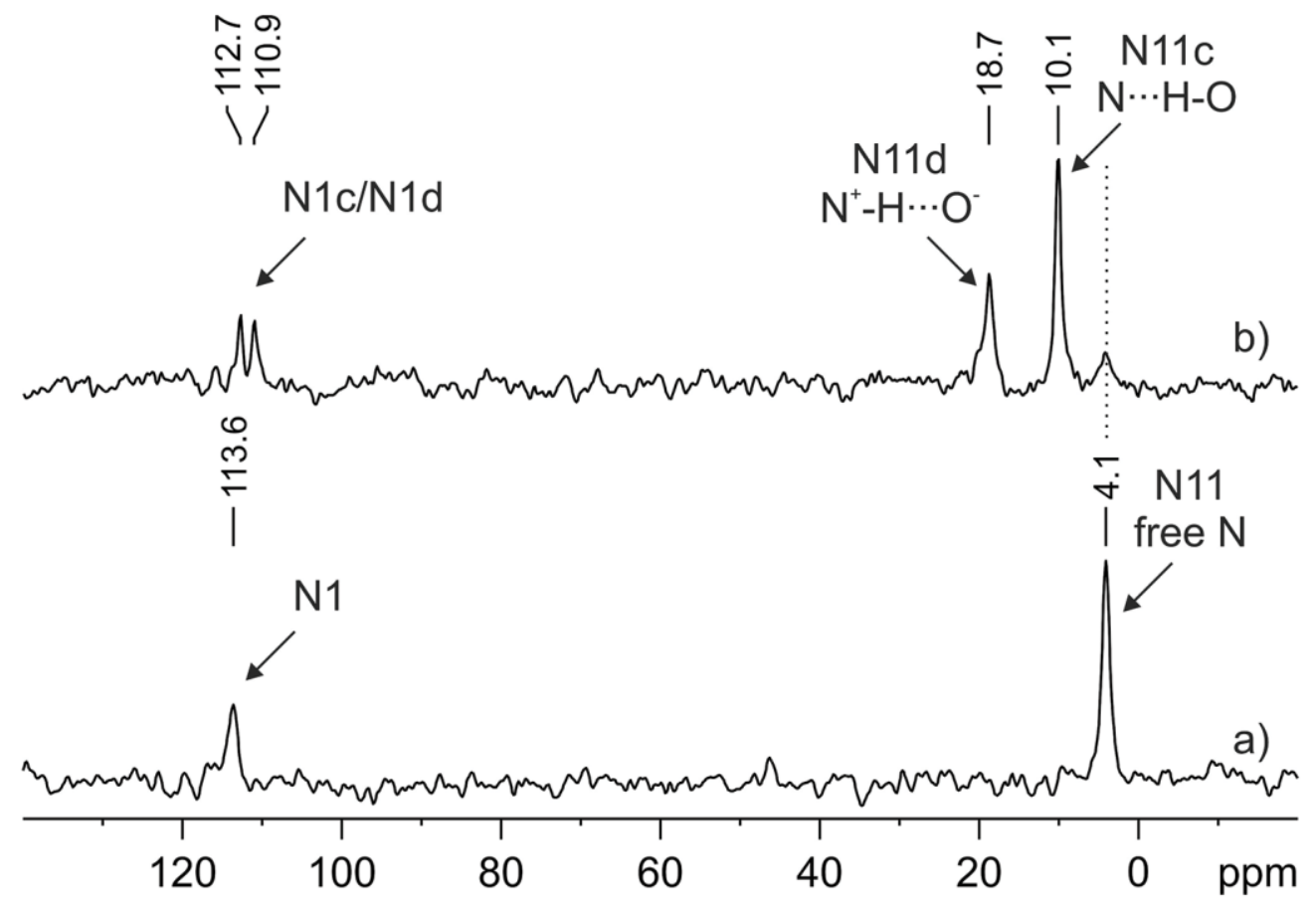




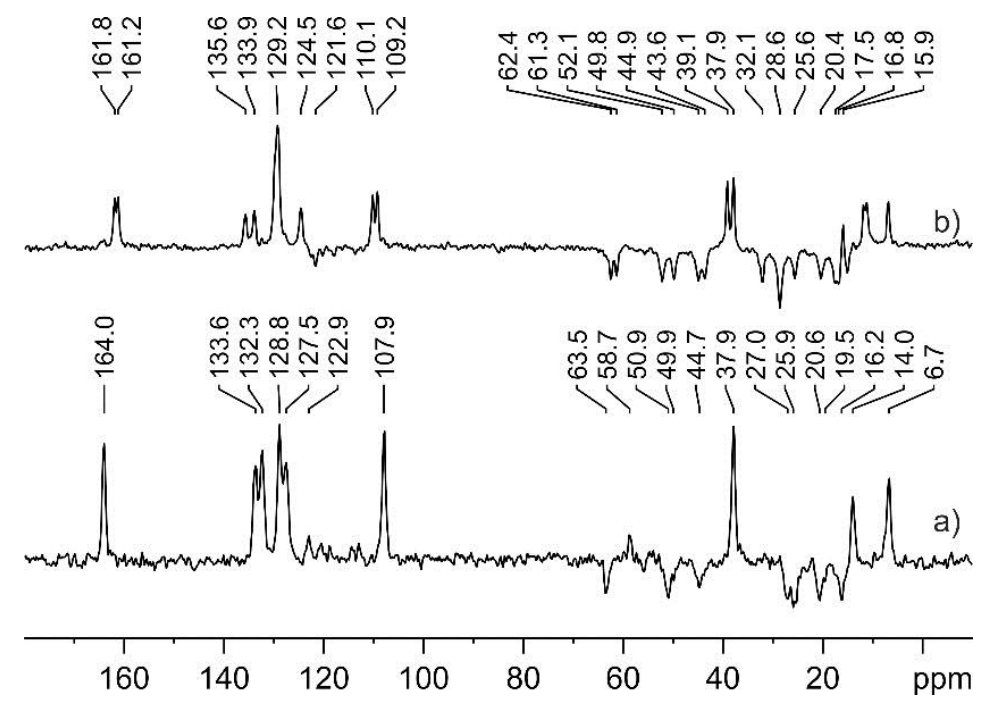

Figure S1. ${ }^{13} \mathrm{C}(100.64 \mathrm{MHz})$ CPPISPI spectral editing experiment with chemical shifts of (a) pure vinpocetine and (b) 1 recorded with a spinning speed of $12 \mathrm{kHz}$. 